\title{
FAILURE SURFACE ANALYSIS OF POLYIMIDE/TITANIUM NOTCHED COATING ADHESION SPECIMENS
}

\author{
Rachel Knudsen Giunta* \\ Materials Engineering Science \\ Ronald G. Kander \\ Materials Science and Engineering \\ Virginia Polytechnic Institute and State University \\ Blacksburg, VA 24061-0237 \\ *Current address: Sandia National Laboratories \\ Albuquerque, NM 87185-0958
}

Keywords: Polyimide, Interphase, PETI-5 Adhesive, Chromic Acid Anodization, Ti-6Al4V, Pore Penetration

R. K. Giunta and R. G. Kander

Body

Page 1 of 38 


\begin{abstract}
Adhesively bonded joints of LaRCTM PETI-5, a phenylethynyl-terminated polyimide, with chromic acid anodized titanium were fabricated and debonded interfacially. The adhesive-substrate failure surfaces were investigated using several surface analysis techniques. From Auger spectroscopy, field emission scanning electron microscopy, and atomic force microscopy studies, polymer appears to be penetrating the pores of the anodized substrate to a depth of approximately $100 \mathrm{~nm}$. From x-ray photoelectron spectroscopy data, the polymer penetrating the pores appears to be in electrical contact with the titanium substrate, leading to differential charging. These analyses confirm that the polymer is becoming mechanically interlocked within the substrate surface.
\end{abstract}




\section{DISCLAIMER}

This report was prepared as an account of work sponsored by an agency of the United States Government. Neither the United States Government nor any agency thereof, nor any of their employees, make any warranty, express or implied, or assumes any legal liability or responsibility for the accuracy, completeness, or usefulness of any information, apparatus, product, or process disciosed, or represents that its use would not infringe privately owned rights. Reference herein to any specific commercial product, process, or service by trade name, trademark, manufacturer, or otherwise does not necessarily constitute or imply its endorsement, recommendation, or favoring by the United States Government or any agency thereof. The views and opinions of authors expressed herein do not necessarily state or reflect those of the United States Government or any agency thereof. 


\section{DISCLAIMER}

Portions of this document may be illegible in electronic image products. Images are produced from the best available original document. 


\section{INTRODUCTION}

When bonded joints are subjected to harsh environmental conditions, failures tend to occur near the interface. ${ }^{1-5}$ Therefore, the long-term durability of adhesive joints is critically dependent on the three-dimensional adhesive/substrate interphase. According to Venables, ${ }^{6}$ mechanical interlocking is critical for good initial bond strength and long-term durability of metal-polymer bonds. Mechanical interlocking, or keying, involves the flow of adhesive into interstices of the substrate surface. Subsequent solidification locks the adhesive into the well. Mechanical interlocking is believed to significantly contribute to the adhesion of substrates that exhibit microroughness, such as metal surfaces treated with chromic acid anodization (CAA) or sodium hydroxide anodization (SHA).

Analysis of mechanical interlocking at the adhesive-substrate interphase is essential in the study of the durability of high-performance adhesives. A current area of adhesive durability research is the development of critical technologies for elevated temperature aerospace applications. High performance polymeric adhesives are needed for bonding titanium in structural components of aircraft. These joints have been designed to withstand a temperature of $177^{\circ} \mathrm{C}$ for 60,000 hours while maintaining desirable mechanical properties.

LaRCTM PETI-5, ${ }^{8-16}$ a phenylethynyl-terminated polyimide adhesive, was developed for potential use in high-temperature aircraft applications. The structure of the PETI-5 precursor, which undergoes chain extension and crosslinking of the end groups during cure, is illustrated in Figure 1. Prior to cure, the molecular weight of PETI-5 used in the 
current study is $5,000 \mathrm{~g} / \mathrm{mol}$. After an elevated temperature cure, the lightly crosslinked, amorphous polyimide has a glass transition temperature of $260^{\circ} \mathrm{C}$. The potential for use of PETI-5 in the aerospace industry has prompted numerous investigations of the durability of these adhesive joints with Ti-6Al-4V, ${ }^{12,16,17}$ an alloy of $90 \%$ titanium, $6 \%$ aluminum, and $4 \%$ vanadium.

The objective of the current study is to determine whether PETI-5 adhesive is penetrating the pores of the anodized titanium substrate during processing. Although previous studies of polyimides bonded to anodized substrates have stated the assumption that the adhesive is penetrating the pores of the substrate, ${ }^{18}$ direct evidence of penetration has not been previously reported. Filbey and Wightman ${ }^{19}$ found that an epoxy penetrated the pores of CAA Ti- $6 \mathrm{Al}-4 \mathrm{~V}$, one of the limited number of pore penetration studies that have been reported. ${ }^{19,20}$ The difference in the chemistry and molecular structure of epoxies versus polyimides prevent one from assuming their penetration behavior will be similar. In fact, the higher molecular weight and more rigid backbone structure of polyimides would render them less able to penetrate nanometer-scale pores than epoxies. Here, the penetration of PETI-5 into the pores of CAA Ti-6Al-4V is investigated using several surface analysis techniques. 


\section{EXPERIMENTAL}

\section{Materials}

\section{Adhesives}

LaRC PETI-5, a phenylethynyl-terminated polyimide adhesive, was received from Imitec, ${ }^{\mathrm{TM}}$ Schenectady, NY, as an amic acid solution at $35 \%$ solids (w/w) in N-methyl pyrrolidinone (NMP). The calculated molecular weight of uncured PETI-5 was 5,000 $\mathrm{g} / \mathrm{mol}$. Upon cure, PETI-5 is a thermoset with a $T_{g}$ of $260^{\circ} \mathrm{C}$.

PETI-5 adhesive tape was fabricated from the amic acid solution and used in the preparation of adhesive specimens. An E-glass scrim cloth, $0.08 \mathrm{~mm}$ thick with A1100 finish arranged in a $0^{\circ} / 90^{\circ}$ plain weave, was stretched onto a frame and dried at $150^{\circ} \mathrm{C}$ for one hour prior to application of the adhesive. The cloth was impregnated with adhesive by applying PETI-5 as a poly(amic acid) solution in NMP using a natural bristle paintbrush. Each coat of PETI-5 solution was dried for one hour at $175^{\circ} \mathrm{C}$. Several coats were applied to the glass cloth until the desired thickness of $0.30 \mathrm{~mm}$ was obtained. Further drying cycles up to $250^{\circ} \mathrm{C}$ were performed to reduce the volatile content of the tape to less than $2.5 \%$.

\section{Substrates}

The substrates of all adhesive specimens were Ti-6Al-4V. Substrates, which measured $203 \times 12.7 \times 1.78 \mathrm{~mm}$, were received from President Titanium Co., Hanson, MA. 
Following degreasing of the substrates, they were anodized in chromic acid at $5.0 \mathrm{~V}$ and 0.2 amps for 20 minutes. After drying in a $60^{\circ} \mathrm{C}$ oven, the PETI- 5 coupons were primed using a $16 \%$ solids solution of PETI-5 amic acid in NMP. The primed coupons were dried at $225^{\circ} \mathrm{C}$ for 1 hour.

\section{Adhesive Specimens}

Notched coating adhesion (NCA) specimens ${ }^{21,22}$ of PETI-5 bonded to CAA Ti-6Al-4V were analyzed for the current study. NCA specimens were selected to achieve interfacial failure, along with reasons that are outside of the scope of the current discussion. ${ }^{23}$

Specimens were manufactured in an autoclave under vacuum using a bonding pressure of $690 \mathrm{kPa}$ at $350^{\circ} \mathrm{C}$ for 30 minutes and $371^{\circ} \mathrm{C}$ for 30 minutes. Two plies of adhesive in scrim cloth were used, and bondlines were controlled to $0.25 \mathrm{~mm}$.

Figure 2 illustrates an NCA specimen during debonding of the adhesive from the substrate. To debond the specimens along the adhesive/substrate interface, an initial cut was made between the adhesive and substrate of the NCA specimens by driving a razor blade into the interface. Specimens were then placed in a hand-held three-point-bend fixture and bent so that the adhesive coating was in tension. The razor-induced debond propagated to form a sharp-tipped debond between adhesive and substrate. Following initiation of the pre-crack, specimens were fully debonded by gripping the substrate in an Instron test frame and pulling the specimens in tension at a strain rate of $2.5 \mathrm{~mm} / \mathrm{min}$. This was accomplished on a $9 \mathrm{kN}$ Instron test frame equipped with a System 4000 data acquisition system. 


\section{Characterization}

\section{Optical Microscopy}

Optical micrographs of failure surfaces were obtained using an Olympus BH-2 optical microscope. All failure surfaces, adhesive and metal failure sides, were analyzed.

\section{Auger Electron Spectroscopy}

Depth profiling was performed on a Perkin-Elmer model 610 scanning Auger system using a single pass cylindrical mirror analyzer with electron excitation from a coaxial electron gun. The minimum electron beam diameter is less than $100 \mathrm{~nm}$. The sputter rate was calibrated using a tantalum standard. AES was performed on the metal failure surface of three debonded specimens.

Field Emission Scanning Electron Microscopy

FE-SEM was performed on a LEO model 1550 Field Emission Scanning Electron Microscope at 0.25 to $2.0 \mathrm{kV}$. The adhesive and titanium failure surfaces of three debonded specimens were analyzed. Samples were not sputter-coated, and no charging was observed.

\section{Atomic Force Microscopy}

A Digital Instruments Dimension 3000 Atomic Force Microscope using the Nanoscope IIIa controller was used in tapping mode to obtain height and phase AFM images. The adhesive and metal failure surfaces of three specimens were analyzed. 


\section{$X$-ray photoelectron spectroscopy}

To determine the atomic concentration of elements on the failure surfaces of NCA specimens, XPS was performed using a Perkin Elmer model 5400 spectrometer. A Mg $\mathrm{K} \alpha \mathrm{x}$-ray source operated at $14 \mathrm{kV}$ (300 watts) of power was used to analyze a spot size of $1.0 \times 3.0 \mathrm{~mm}$ on the specimen surfaces. Typical sampling depths are 5 to $10 \mathrm{~nm}$, and the detection limits of the instrument reflect an atomic concentration of approximately $0.2 \%$. Both failure surfaces of six specimens were analyzed. Binding energies were standardized to the hydrocarbon portion of the spectrum at $285.0 \mathrm{eV}$.

\section{RESULTS AND DISCUSSION}

Before looking for experimental evidence of pore penetration, we assessed if it is possible for PETI-5 polymer molecules to penetrate the porous oxide layer of CAA titanium. FE-SEM images of CAA Ti-6Al-4V are shown in Figure 3. The dark circular regions are pores in the CAA oxide layer, approximately $30 \mathrm{~nm}$ in diameter. When PETI-5 is applied to the anodized substrate surface, it is a primer in the form of a $16 \%$ solids amic acid solution in NMP. Using gel permeation chromatography, the radius of gyration of the PETI-5 amic acid solution was determined. The number average radius of gyration was found to be $3.6 \mathrm{~nm}$, with weight average and z-average radii of gyration of 4.8 and 5.7 $\mathrm{nm}$, respectively. The diameter of the coiled polymer chain conformation, therefore, is less than the diameter of the substrate pores. Thus, it is reasonable to assume that PETI-5 amic acid can penetrate the pores of the CAA substrate. 


\section{Optical Microscopy}

Titanium was observed by optical microscopy on the adhesive failure surfaces of PETI-5 NCA specimens. In Figure 4, the adhesive and metal failure surfaces of a PETI-5 specimen are shown. These micrographs were taken in the same spot on corresponding adhesive and metal failure surfaces. Since high-quality color micrographs were not available, the original black and white micrographs were colorized to reproduce the colors that were actually observed using the optical microscope. On both failure surfaces, the light gray regions correspond to metal or metal oxide. Here, failure occurred in one of three locations: 1) through the metal oxide layer, 2) between the metal and metal oxide, or 3) through the metal itself. On the adhesive failure surface, dark brown features are observed which are mirror images of blue features on the metal failure surface. The dark brown color on the adhesive failure surface is indicative of exposed PETI-5 adhesive. The blue color on the metal failure surface is consistent with the surface of anodized titanium. Although this appears to indicate interfacial failure between adhesive and substrate, evidence of polyimide adhesive on the metal failure surface was consistently detected by XPS. Thus, there seems to be either a thin, optically transparent coating of polyimide on the blue oxide layer or embedded within the pores of the oxide. To further investigate this region, Auger depth profiling, field emission SEM, and atomic force microscopy were utilized.

\section{Auger Electron Spectroscopy}

Auger depth profiling of a PETI-5 metal failure surface, Figure 5, illustrates that carbon and titanium coexist in the top 75 to $100 \mathrm{~nm}$ of the failure surface. While this does imply 
the presence of polyimide at this depth, Auger data alone cannot be interpreted as confirmation of mechanically interlocked polymer. Auger spectroscopy cannot distinguish between carbon as polyimide and carbon that may be present as a contaminant. However, if we tentatively assume that the presence of carbon represents polymer, we can construct a simple model of the interfacial region. Beyond the depth at which carbon is detected, oxygen (indicative of metal oxide) is present through an additional $50 \mathrm{~nm}$. Deeper than this, only titanium and aluminum are detected. Thus, the polymer does not appear to penetrate the entire thickness of the titanium oxide layer. The validity of this interpretation of the Auger data can now be examined using additional surface analysis techniques. The model interphase is illustrated in Figure 6. The region in which adhesive and metal oxide are assumed to be present will be referred to as oxide $\mathrm{A}$ and the area in which there is only metal oxide is referenced as oxide B.

\section{Scanning Electron Microscopy}

Field emission SEM was performed on the adhesive and metal failure surfaces of PETI-5 NCA specimens. Figure 7 is a FE-SEM of the metal failure surface. The features visible at this magnification are similar to those observed by optical microscopy. Dark areas correspond to the blue regions of Figure 4 (b), the anodized substrate surface, and light areas are exposed metal or metal oxide, present below the anodized region. Enlarging the center of Figure 7 by a factor of five, additional features become visible in Figure 8 . The dark region on the left is the anodized substrate surface. The pores in the anodized oxide layer, which we believe to be infiltrated with polyimide adhesive, are clearly visible in this region. The failure here occurred between the bulk adhesive and the upper surface of 
oxide A. The porous structure of the lighter colored region on the right side of the micrograph is apparent. Failure here occurred within the porous oxide layer. In the upper right corner of the micrograph, there is a circular region in which the porosity is not well defined. Here, it appears that the failure occurred at the interface of the porous and nonporous oxides.

In Figure 9, the edge of a porous oxide/polyimide region can be seen in another FE-SEM of a metal failure surface. This micrograph illustrates the sponge-like morphology through the thickness of the oxide layer. One can also see, from the scale of this micrograph, that the thickness of the oxide/polyimide layer is on the order of $100 \mathrm{~nm}$, in agreement with the Auger depth profiling data.

Additional features are observed in FE-SEMs of adhesive failure surfaces. Figure 10 is an FE-SEM of an adhesive failure surface. The dark region at the top of this micrograph corresponds to the dark brown adhesive observed by optical microscopy, Figure 4 (a), while the lighter region on the bottom corresponds to the light gray metal oxide. Across the top of this micrograph, the ductility of the polymer is evident by the drawing and fibrillation that occurred as the failure propagated from the right to the left of this micrograph. In the lower half of the micrograph, the titanium failure region is observed. On this metal oxide surface, round features of two sizes can be seen. These features are enlarged in Figure 11. The larger features are irregular in shape and range from 150 to $400 \mathrm{~nm}$ across. The smaller features are round, uniform, and less than $50 \mathrm{~nm}$. The size, shape, and spatial distribution of the smaller features are consistent with the pores on the 
anodized titanium surface in Figure 3 . Thus, we believe these are either the pores themselves or polymer that has been pulled from the pores on the metal failure surface.

\section{Atomic Force Microscopy}

Based on FE-SEM observations, atomic force microscopy was used to determine if these features were raised (polymer) or indented (pores). The larger features are believed to be the result of the failure propagating through the walls of several pores in close proximity. AFM images of the titanium failure surface and the adhesive failure surface are shown in Figure 12 and Figure 13, respectively. Note that the scales in the two micrographs are different. The $30 \mathrm{~nm}$ pores cannot be resolved by AFM; however, the larger features (approximately $200 \mathrm{~nm}$ ) observed in Figure 11 appear in a periodic fashion in the AFM images.

In the AFM height images, on the left in each figure, lighter shades correspond to higher features. In Figure 12, the metal failure surface, the dark background is exposed oxide. The diagonal strip of lighter color is the anodized oxide layer (i.e. the blue region of Figure 4). The small features on the background oxide surface are darker than the background and therefore indented. On the adhesive failure surface, Figure 13, features of approximately the same size are raised, illustrated by the fact that they are lighter in color than the background. The matching raised features on the adhesive failure surface and indented features on the metal failure surface support the assertion that polyimide adhesive is embedded in the pores of the CAA oxide layer. From the model proposed in Figure 6, the failure within the oxide layer appears to be occurring at the interface of oxide $\mathrm{A}$ and oxide $\mathrm{B}$. The raised features on the adhesive failure surface would then be 
attributed to polymer embedded in the oxide, and the indented features in the metal oxide layer would be holes left in the oxide layer, having been pulled out by the polymer. Had the failure occurred through porous oxide that did not contain adhesive, these features would have appeared indented on both failure surfaces.

Additional information is obtained from the AFM phase images. Darker regions of the phase image indicate a higher phase lag that, in general, means dark areas are softer than light areas. The diagonal strip on the metal failure surface, Figure 12, is both higher and softer than the surrounding area. If there were no polymer embedded in the porous oxide, it would not be softer than the surrounding metal oxide. This again confirms that the substrate pores contain polyimide. All surface analysis data appears to validate the model in Figure 6. Thus, it is concluded that PETI-5 is penetrating the pores of the CAA substrate and becoming mechanically interlocked.

\section{X-ray Photoelectron Spectroscopy}

XPS analysis of adhesive failure surfaces of PETI-5 NCA specimens supports the conclusion that the polymer is imbedded in the pores of the titanium substrate surface. Table 1 lists the XPS photopeak binding energies for $\mathrm{N} 1 \mathrm{~s}, \mathrm{O} 1 \mathrm{~s}$, Ti $2 \mathrm{p}_{3 / 2}, \mathrm{Al} 2 \mathrm{p}_{3 / 2}$, and $\mathrm{F} 1 \mathrm{~s}$ referenced to the $\mathrm{C} 1 \mathrm{~s}$ photopeak at $285.0 \mathrm{eV}$. (Note: aluminum is a component of the Ti-6Al-4V alloy, and fluoride is present from a step in the anodization procedure.) Peaks resulting from elements on the substrate surface, Ti $2 p_{3 / 2}, \operatorname{Al} 2 p_{3 / 2}$, and $F 1 s$, are shifted to a higher binding energy on the adhesive failure surface. These elements are present as $\mathrm{TiO}_{2}, \mathrm{Al}_{2} \mathrm{O}_{3}$, and fluoride ion. On the metal failure side, titanium, aluminum, and fluorine are present at the expected chemical shifts, corresponding to the position of 
the anodized titanium reference and literature values ${ }^{24}$ listed in Table 1. On the adhesive failure surface, however, the $\operatorname{Ti} 2 \mathrm{p}_{3 / 2}, \mathrm{Al} 2 \mathrm{p}_{3 / 2}$, and $\mathrm{F} 1 \mathrm{~s}$ peaks are shifted to approximately $2.5 \mathrm{eV}$ higher binding energy. In addition, the low energy (organic) portion of the $\mathrm{O} 1 \mathrm{~s}$ spectrum has shifted by $2.2 \mathrm{eV}$ to overlap the organic portion of the spectrum. We believe that the shift in binding energy on the adhesive failure surface is the result of differential charging. This is analogous to the observation by Pertsin $e t$ al. ${ }^{25}$ of differential charging on a sample consisting of platinum islands on a polymer film.

XPS analysis is prone to differential charging in situations where analysis surfaces exhibit inhomogeneous conductivity and electron affinity ${ }^{26-29}$ While performing XPS, the outgoing photoelectron leaves a positive charge on the sample surface. In an insulator, the spectrometer cannot conduct electrons to the sample surface to compensate for this charge. Consequently, a positive charge is built up on the specimen under analysis. While uniform charging of a non-conductor shifts the whole spectrum, generally to higher binding energies, differential charging causes different components of a sample to shift by different amounts. Thus, the typical means of correcting for uniform charging, such as the use of adventitious carbon as a binding energy reference, supply erroneous binding energies for a portion of the sample components. ${ }^{30}$

In the current example, the charging of the adhesive and metal oxide is non-uniform. In referencing the entire spectrum to the $\mathrm{C} 1 \mathrm{~s}$ photopeak at $285.0 \mathrm{eV}$, we have corrected for the charging of the organic adhesive but have displaced the positions of the substrate elements by $2.5 \mathrm{eV}$. Ti $2 \mathrm{p}_{3 / 2}$ XPS photopeaks from the metal and adhesive failure 
surfaces of PETI-5 NCA specimens are given in Figure 14, illustrating the shift caused by differential charging on the adhesive failure surface.

An additional effect, also believed to be caused by differential charging, is observed in the XPS data. The C 1s XPS photopeaks of the metal and adhesive failure surfaces are shown in Figure 15. While both $\mathrm{C}$ 1s photopeaks have been resolved with four sub-peaks in approximately the same position, the peak at $287.0 \mathrm{eV}$ on the adhesive failure surface is considerably larger than the corresponding peak on the metal failure surface. The peak position on the adhesive failure surface is also shifted to a slightly higher binding energy than that observed on the metal failure surface, $286.4 \mathrm{eV}$. Average binding energies for the four $\mathrm{C}$ 1s sub-peaks on the adhesive and metal failure surfaces are listed in Table 2. The peak at $286.4 \mathrm{eV}$ is assigned to carbon single bonded to oxygen. An additional feature obscures the $\mathrm{C}-\mathrm{O}$ peak on the adhesive failure surface. The peak at $286.9 \mathrm{eV}$ is believed to arise from the $\mathrm{C}-\mathrm{H}$ component of the PETI-5 adhesive that is embedded in the porous $\mathrm{TiO}_{2}$ substrate surface, the adhesive portion of oxide $\mathrm{A}$. If the polymer is in electrical contact with the titanium, they are expected to undergo differential charging in unison. ${ }^{25}$ In Figure 16, the shifted component of the $\mathrm{C}$ 1s photopeak is plotted as a function of atomic concentration of titanium. The percentage of the $\mathrm{C} 1 \mathrm{~s}$ peak that is shifted to higher binding energy is proportional to the amount of titanium detected on the surface. The shifted component has been normalized by the total carbon concentration. The $R^{2}$ value of 0.88 indicates a strong linear fit, and the p-value of 0.017 indicates a 98.3\% probability that the trend is significant. The relationship between the titanium detected on the surface and the amount of shifted carbon illustrates that the shifted carbon 
originates from polymer embedded in the pores of the oxide. To further illustrate this point, the $\mathrm{C}$ 1s photopeaks of three adhesive failure surfaces are presented in Figure 17 along with the titanium coverage detected by XPS in the same sample. This clearly illustrates the decrease in the shifted portion of the $\mathrm{C}-\mathrm{H}$ photopeak with decreasing titanium coverage. The charging component of the $\mathrm{C}-\mathrm{H}$ peak, therefore, is attributed to polymer that is embedded in the porous oxide, or oxide A from the model discussed previously.

\section{CONCLUSIONS}

The interface of PETI-5 with CAA Ti-6Al-4V was investigated using several surface analysis techniques. From Auger spectroscopy, field emission SEM, and AFM studies, polymer is believed to be penetrating the pores of the anodized substrate to a depth of approximately $100 \mathrm{~nm}$. From XPS data, this polymer appears to be in electrical contact with the titanium oxide, leading to differential charging. These analyses confirm that the polymer is becoming mechanically interlocked within the substrate surface.

\section{ACKNOWLEDGMENTS}

The authors gratefully acknowledge the Center for Adhesive and Sealant Science at Virginia Tech and the Adhesive and Sealant Council Education Foundation for financial support. In addition, we would like to thank several members of the Composites and Polymers Branch, NASA Langley Research Center. We thank Terry St. Clair for providing materials and research facilities, and Mia Siochi and Jeffrey Hinkley for 
valuable discussions. Finally, we would like to thank Sandia National Laboratories for support of the preparation of this manuscript. Sandia is a multiprogram laboratory operated by Sandia Corporation, a Lockheed Martin Company, for the United States Department of Energy under Contract DE-AC04-94AL85000.

\section{REFERENCES}

1. P. A. Fay, A. Madison, International J. Adhesion Adhesives, 10, 179 (1990).

2. J. F. Watts, J. E. Castle, T. J. Hall, J. Mater. Sci. Lett., 7, 176 (1988).

3. A. J. Kinloch, J. Adhesion, 10, 193 (1979).

4. A. J. Kinloch, S. J. Shaw, D. L. Hunston, Polymer, 24, 1355 (1983).

5. A. Raveh, D. Marouani, R. Yolgar, J. E. Klemberg-Saphieha, A. Bettelheim, J. Adhesion, 36, 109 (1991).

6. J. D. Venables, J. Mat. Sci., 19, 2431 (1984).

7. P. M. Hergenrother, M. E. Rogalski, Polym. Prepr. 33(1), 354 (1992).

8. J. G. Smith, P. M. Hergenrother, Polym. Prepr., 35(1), 353 (1994).

9. P. M. Hergenrother, J. G. Smith, Polymer 35, 4857 (1994).

10. P. M. Hergenrother, R. G. Bryant, B. J. Jensen, S. J. Havens, J. Polym. Sci. Poly. Chem. Ed., 32, 3061 (1994).

11. J. A. Hinkley and B. J. Jensen, High Perform. Polym. 7(1), 1 (1995).

R. K. Giunta and R. G. Kander

Body

Page 17 of 38 
12. B. J. Jensen, R. G. Bryant, J. G. Smith, and P. M. Hergenrother, J. Adhesion, 54(1), 57 (1995).

13. T. H. Hou, B. J. Jensen, and P. M. Hergenrother, J. of Composite Materials, 30(1), 109 (1996).

14. J. A. Hinkley and B. J. Jensen, High Perform. Polym. 8, 599 (1996).

15. R. J. Cano, M. Rommel, J. A. Hinkley, E. D. Estes, Proceedings of the 41 st International SAMPE Symposium, (G. Schmitt, J. Bauer, C. J. Magurany, C. Hurley, H. Kliger, eds.), 1047 (1996).

16. R. J. Cano and B. J. Jensen, J. Adhesion, 60, 113 (1997).

17. H. Parvatareddy, J. G. Dillard, J. E. McGrath, D. A. Dillard, J. Adhesion Sci. Technol., 12, 615 (1998).

18. V. Ratta, E. J. Stanick, A. Ayambem, H. Parvatareddy, J. E. McGrath, G. L. Wilkes, Polymer, 40, 1889 (1999).

19. J. A. Filbey, J. P. Wightman, J. Adhesion, 28, 1 (1989).

20. D. E. Packham, in Adhesion Aspects of Polymeric Coatings, K. L. Mittal, Ed. (Plenum, New York, 1983).

21. T. Chang, E. A. Sproat, Y. Lai, N. E. Shephard, and D. A. Dillard, J. Adhesion, 60, 153 (1997).

22. D. A. Dillard, B. Chen, T. Chang, and Y.-H. Lai, J. Adhesion, 69, 99 (1999). 
23. R. K. Giunta and R. G. Kander, Polym. Sci and Eng., submitted.

24. XPS International, Inc., http://www.xpsdata.com

25. A. J. Pertsin and Y. M. Pashunin, Appl. Surf. Sci., 44, 171 (1990).

26. G. Polzonetti, M. V. Russo, G. Iucci, A. Furlani, Appl. Surf. Sci., 72, 227 (1993).

27. M. C. Davies, K. M. Shakesheff, A. G. Shard, A. Domb, C. J. Roberts, S. J. B. Tendler, and P. M. Williams, Macromolecules, 29, 2205 (1996).

28. R. A. Haring, S. L. Nunes, R. P. McGouey, E. A. Galligan, W. Volksen, J. L. Hedrick, J. Labadie, J. Mater. Res. 10, 1028 (1995).

29. N. V. Glefond, I. K. Igumenov, Surf. Sci., 275, 323 (1992).

30. W. Grunert, R. Schlogl, H. G. Karge, J. Phys. Chem., 97, 8638 (1993). 
Table 1: Binding energies of XPS photopeaks on PETI-5 failure surfaces, referenced to the $\mathrm{C}$ 1s peak at $285.0 \mathrm{eV}$, with $95 \%$ confidence intervals.

\begin{tabular}{|c|c|c|c|c|}
\hline \multirow[b]{2}{*}{ XPS } & \multicolumn{4}{|c|}{ Binding energy, eV } \\
\hline & Adhesive & Metal failure & $\mathrm{CAA}$ & Literature \\
\hline \multirow{2}{*}{ Photopeak } & failure surface & surface & Ti-6Al-4V & value $^{24}$ \\
\hline & & & reference & \\
\hline $\mathrm{N} 1 \mathrm{~s}$ & $400.5 \pm 0.1$ & $400.5 \pm 0.1$ & $400.3 \pm 0.1^{\mathrm{a}}$ & $400.9^{\mathrm{b}}$ \\
\hline \multirow[t]{2}{*}{ O 1s } & $532.4 \pm 0.2$ & $530.2 \pm 0.1$ & $530.3 \pm 0.1^{c}$ & $530.0^{d}$ \\
\hline & & $531.7 \pm 0.1$ & & $531.1^{\mathrm{e}}$ \\
\hline $\mathrm{Ti} 2 \mathrm{p}_{3 / 2}$ & $461.0 \pm 0.2$ & $458.8 \pm 0.1$ & $458.9 \pm 0.1$ & $458.7^{d}$ \\
\hline $\mathrm{Al} 2 \mathrm{p}_{3 / 2}$ & $77.0 \pm 0.2$ & $74.3 \pm 0.1$ & $74.6 \pm 0.1$ & $74.3^{e}$ \\
\hline F $1 s$ & $687.8 \pm 0.2$ & $685.3 \pm 0.2$ & $685.0 \pm 0.1$ & $685.1^{\mathrm{f}}$ \\
\hline
\end{tabular}

${ }^{a}$ No polyimide was present on the reference sample. The $N 1 \mathrm{~s}$, present at $\sim 1 \%$, is believed to be a contaminant.

${ }^{\mathrm{b}}$ as Kapton ${ }^{\mathrm{TM}}$ polyimide

c The $\mathrm{Al}_{2} \mathrm{O}_{3}$ component appears as an unresolved shoulder.

as $\mathrm{TiO}_{2}$

c as $\mathrm{Al}_{2} \mathrm{O}_{3}$

f as $\mathrm{CaF}_{2}$

R. K. Giunta and R. G. Kander Tables

20 of 38 
Table 2: Binding energies of C 1s XPS sub-peaks on PETI-5 failure surfaces, referenced to the $\mathrm{C}$ 1s $\mathrm{C}-\mathrm{H}$ sub-peak at $285.0 \mathrm{eV}$, with $95 \%$ confidence intervals.

\begin{tabular}{lcc}
\hline & \multicolumn{2}{c}{ Binding energy, $\mathrm{eV}$} \\
\cline { 2 - 3 } XPS Photopeak & Adhesive failure & Metal failure surface \\
& surface & \\
\hline Peak 1 & 285.0 & 285.0 \\
Peak 2 & $286.9 \pm 0.1$ & $286.4 \pm 0.1$ \\
Peak 3 & $288.5 \pm 0.1$ & $288.6 \pm 0.1$ \\
Peak 4 & $291.1 \pm 0.1$ & $291.1 \pm 0.1$ \\
\hline
\end{tabular}



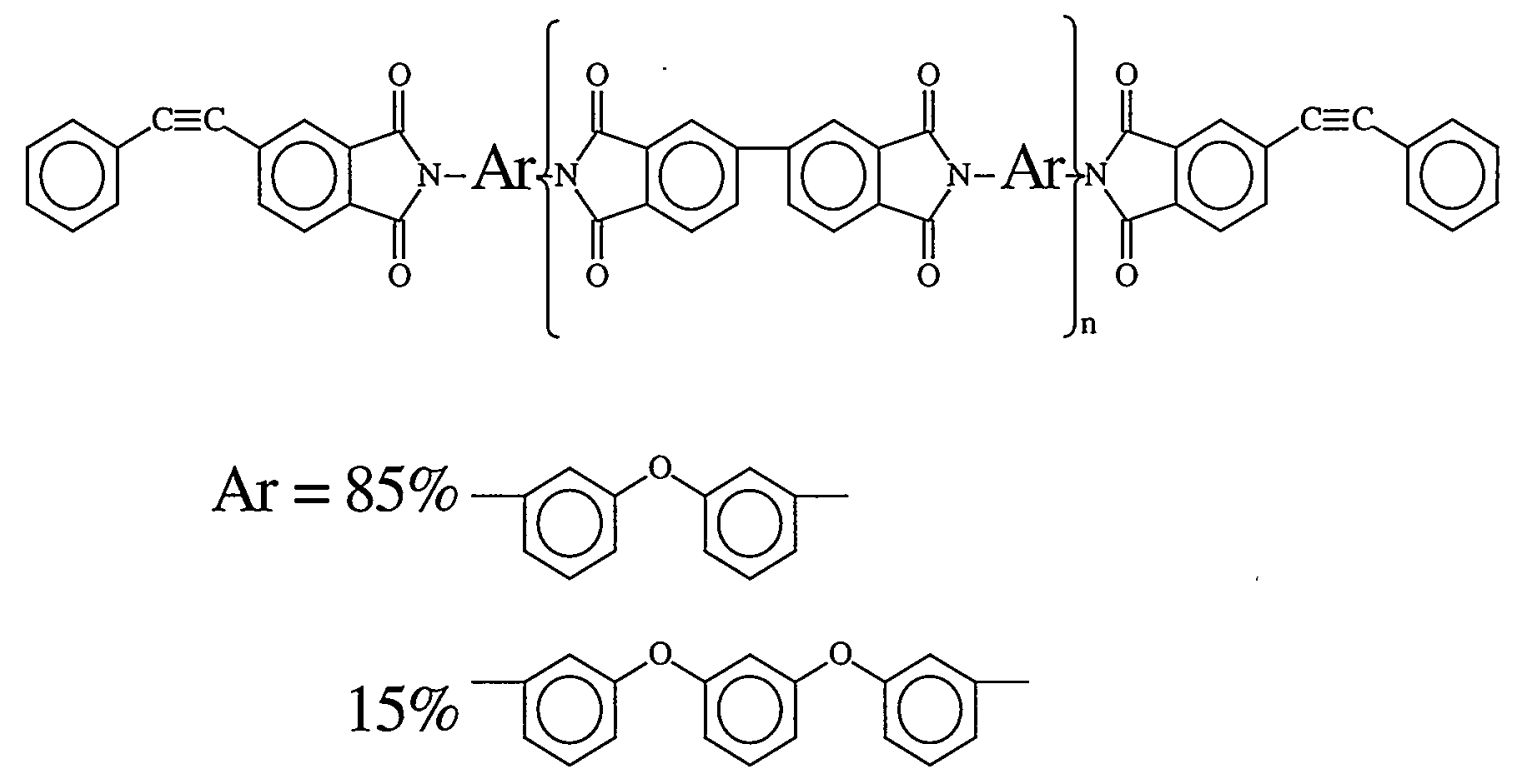

Figure 1: Structure of PETI-5 before cure. $\left\langle M_{n}\right\rangle=5,000 \mathrm{~g} / \mathrm{mol}$ 


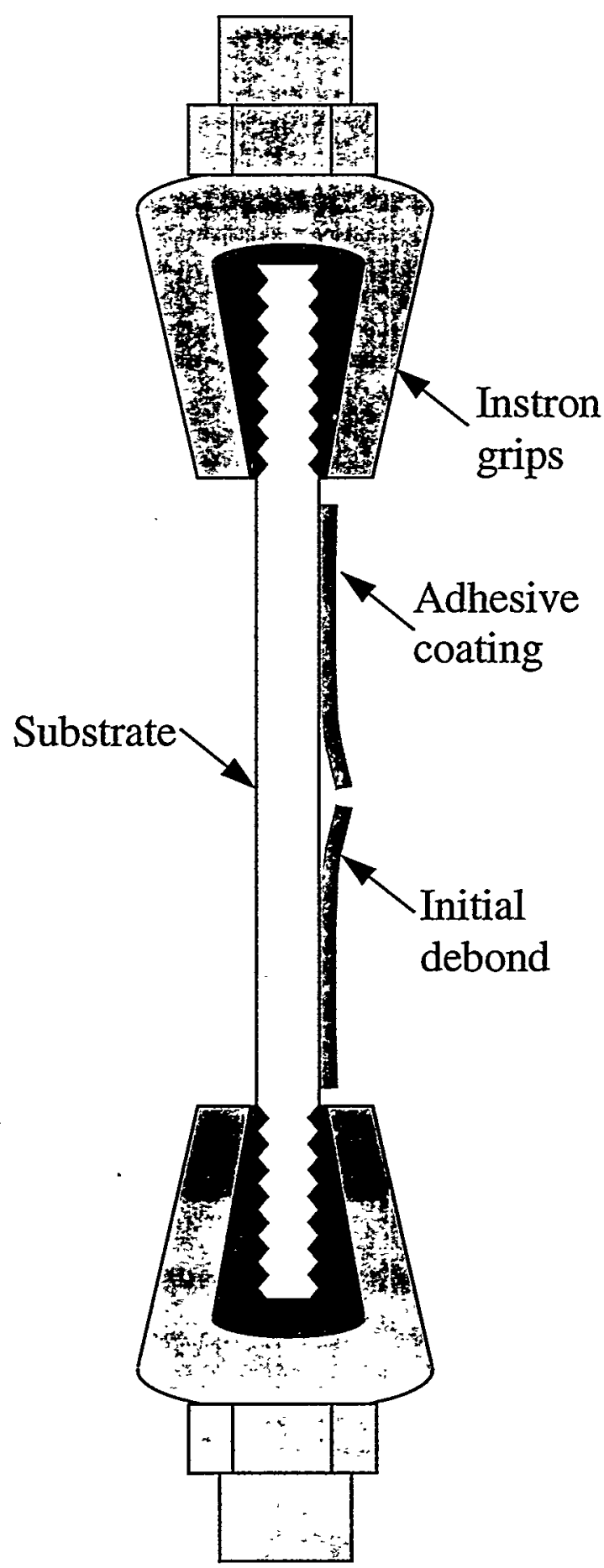

Figure 2: Schematic of a notched coating adhesion specimen during debonding. 


\section{(a)}

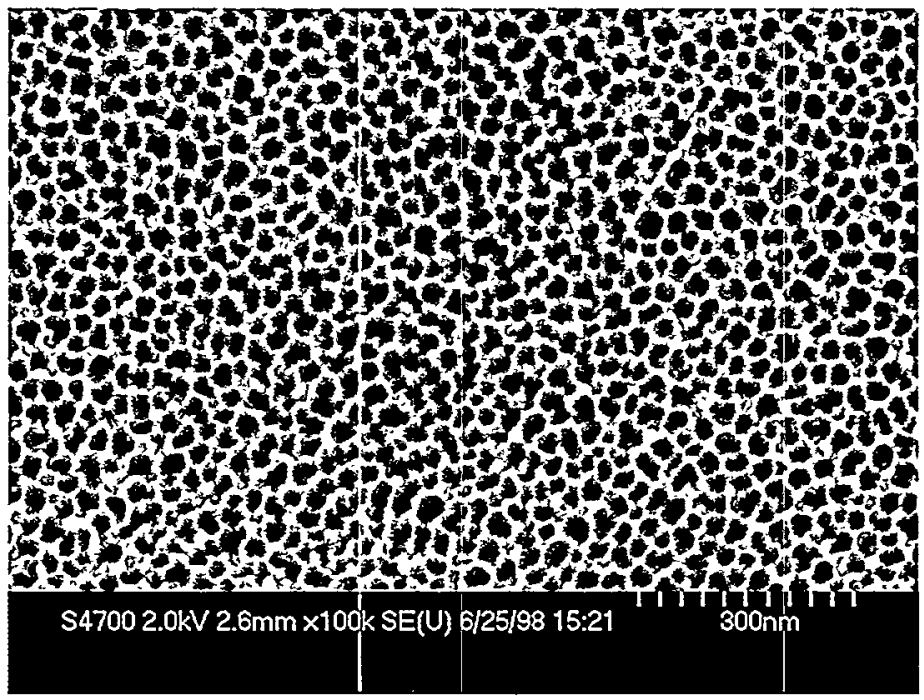

(b)

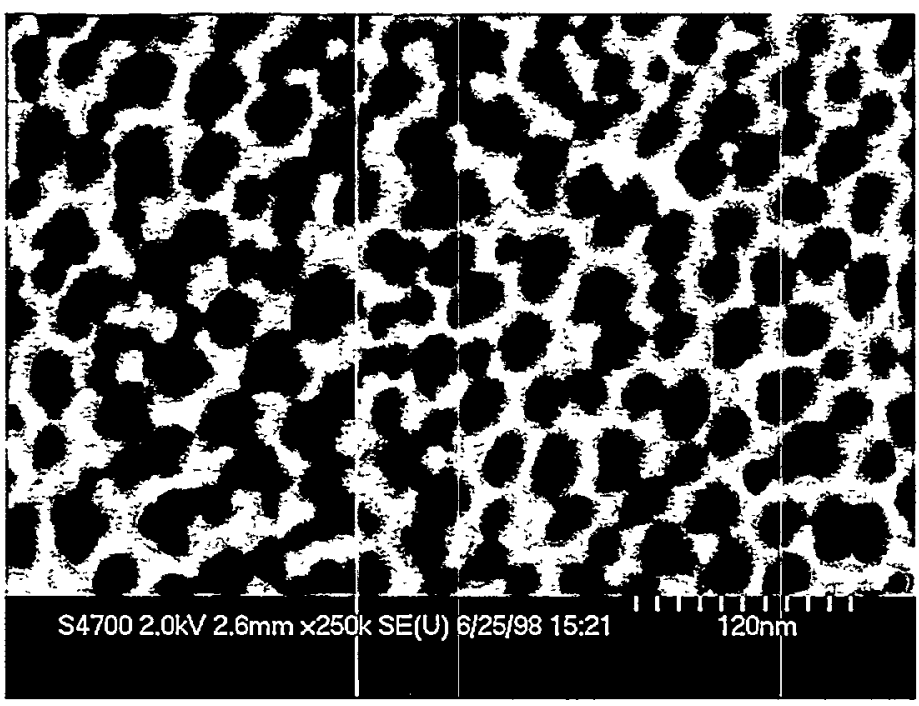

Figure 3: Field emission scanning electron micrographs of a chromic acid anodized Ti-6Al-4V substrate surface. 
(a)

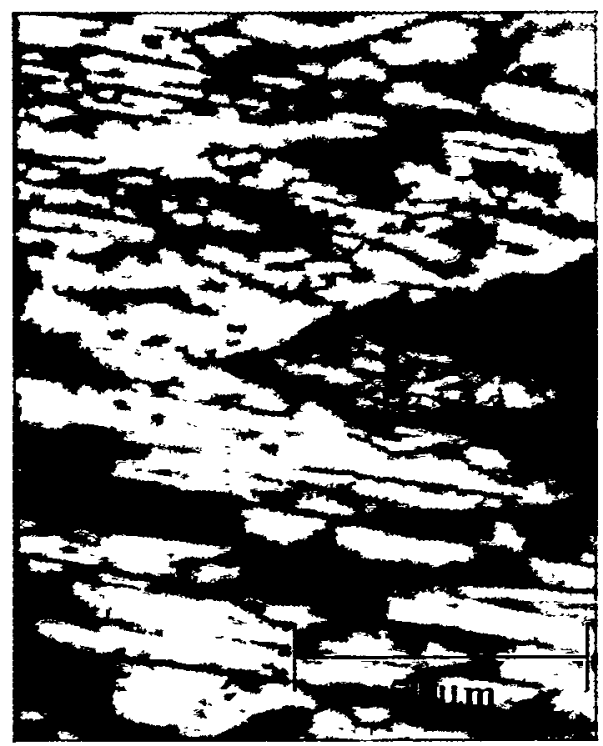

(b)

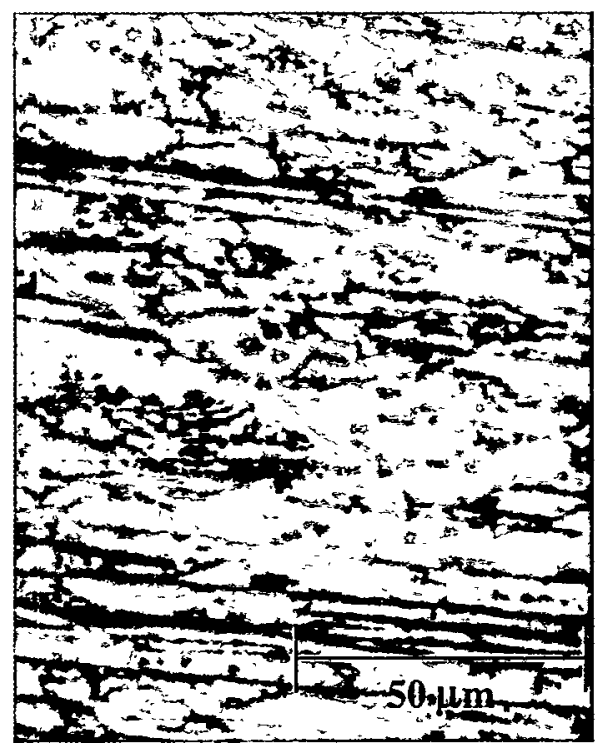

Figure 4: Optical micrographs of failure surfaces of a PETI-5 NCA specimen, (a) adhesive failure surface and (b) titanium failure surface. Micrographs were taken from failure surfaces in locations that were originally bonded to one another. Mirror images of features can be observed on the two failure surfaces. 


\section{Auger Depth Profile}

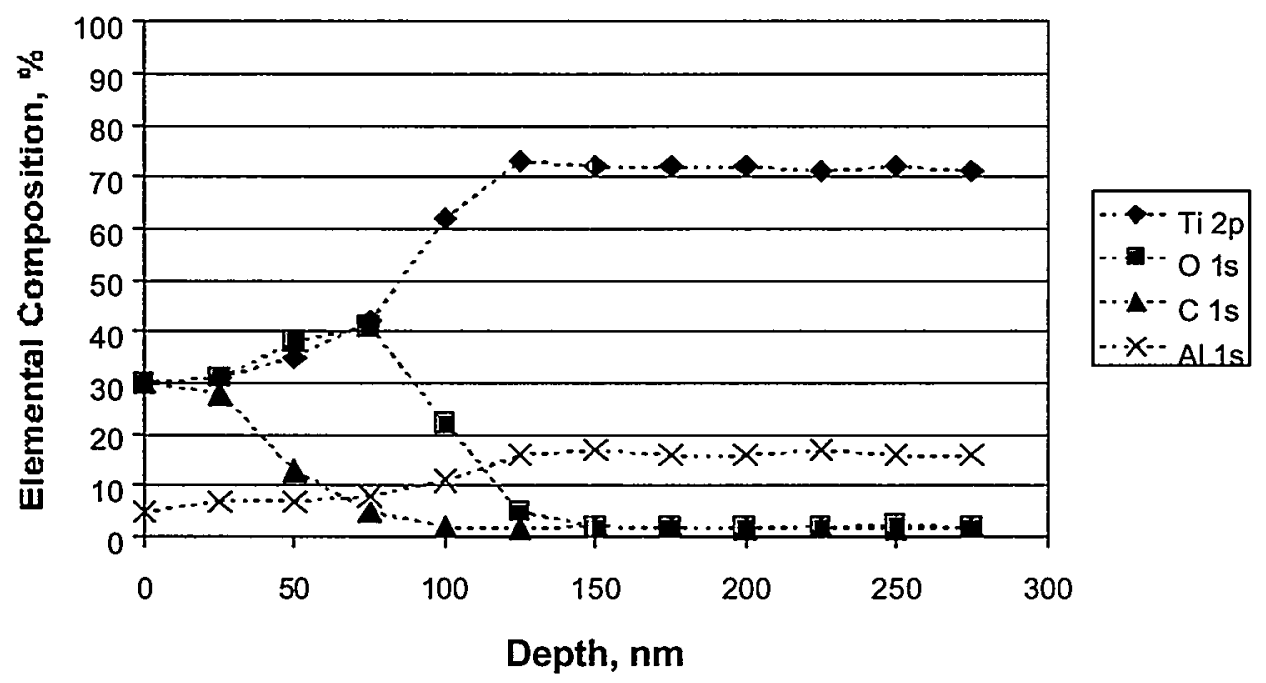

Figure 5: Auger electron spectroscopy depth profile of a PETI-5 metal failure surface from a NCA specimen. 


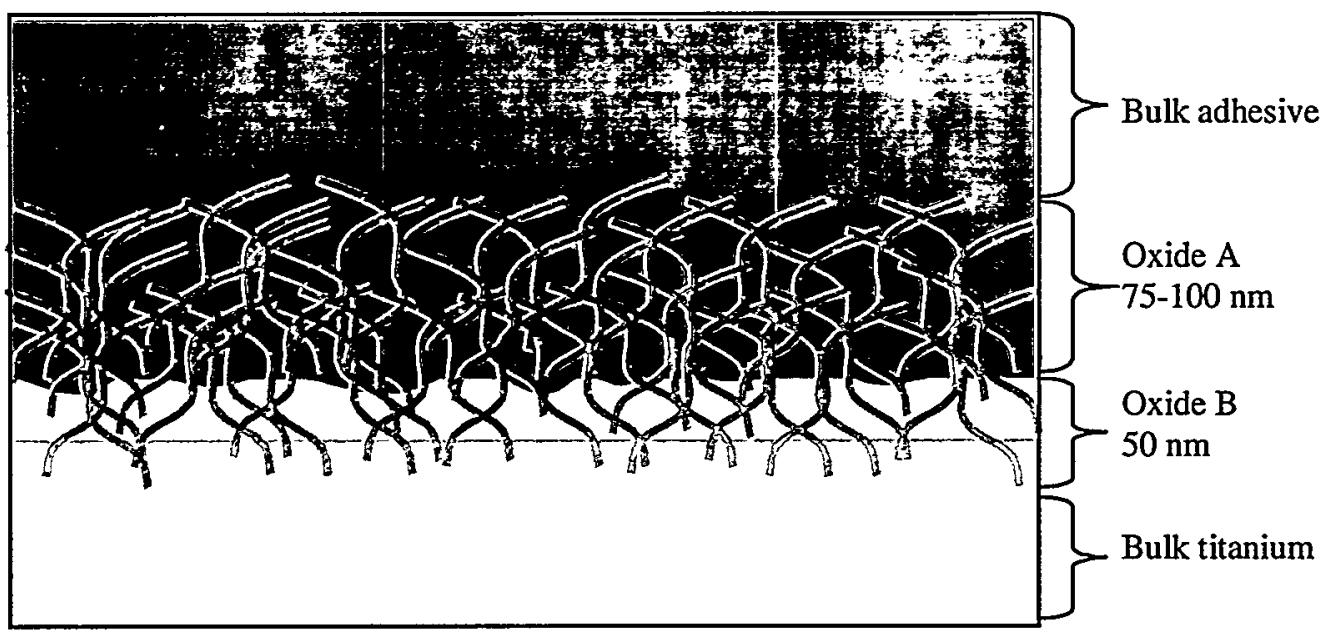

Figure 6: Schematic model of the PETI-5/CAA Ti-6Al-4V interphase based on Auger depth profiling data. Oxide A consists of the porous oxide layer embedded with adhesive. Oxide $B$ is the porous oxide layer that contains no adhesive. 


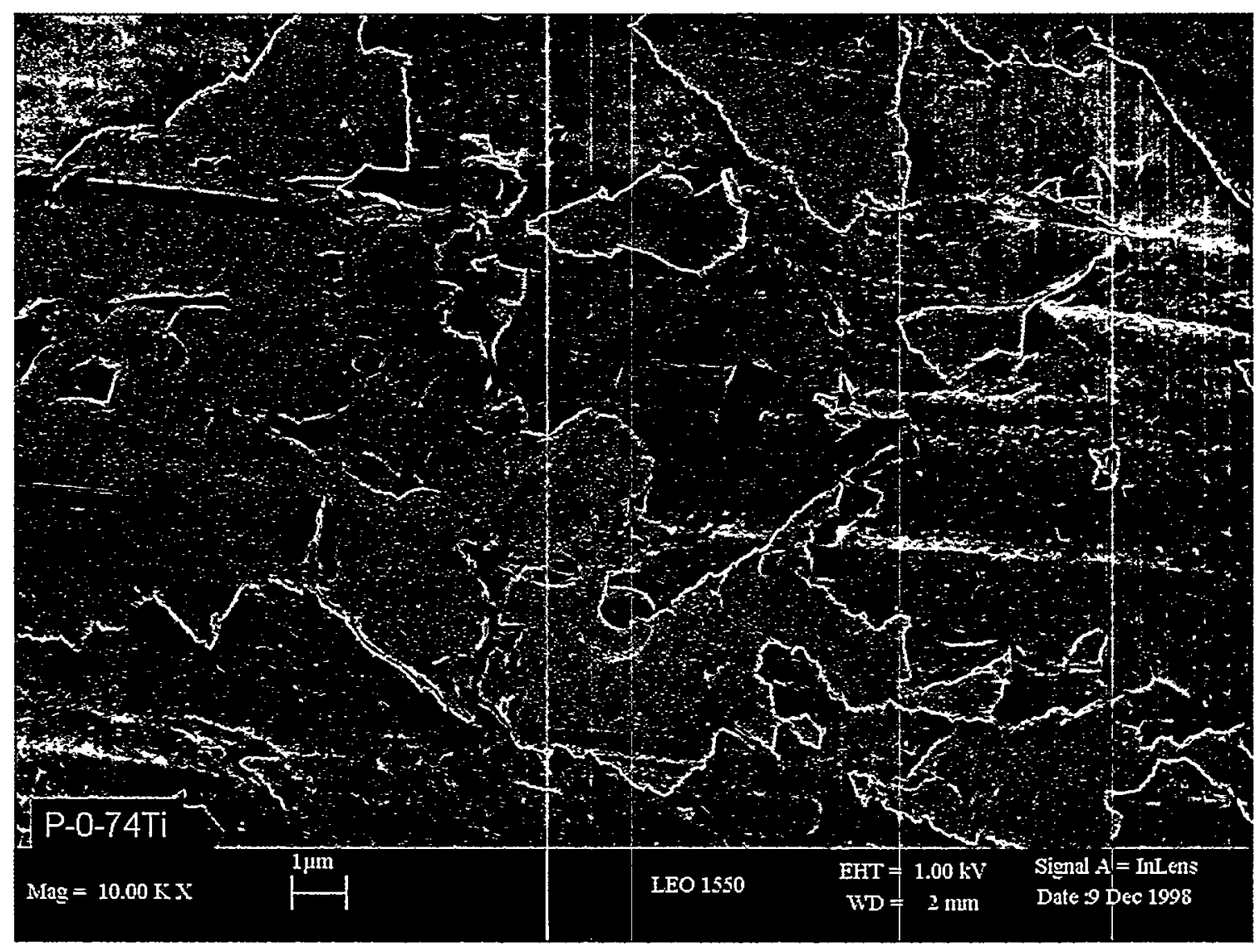

Figure 7: Field emission SEM of the metal failure surface of a PETI-5 NCA specimen. 


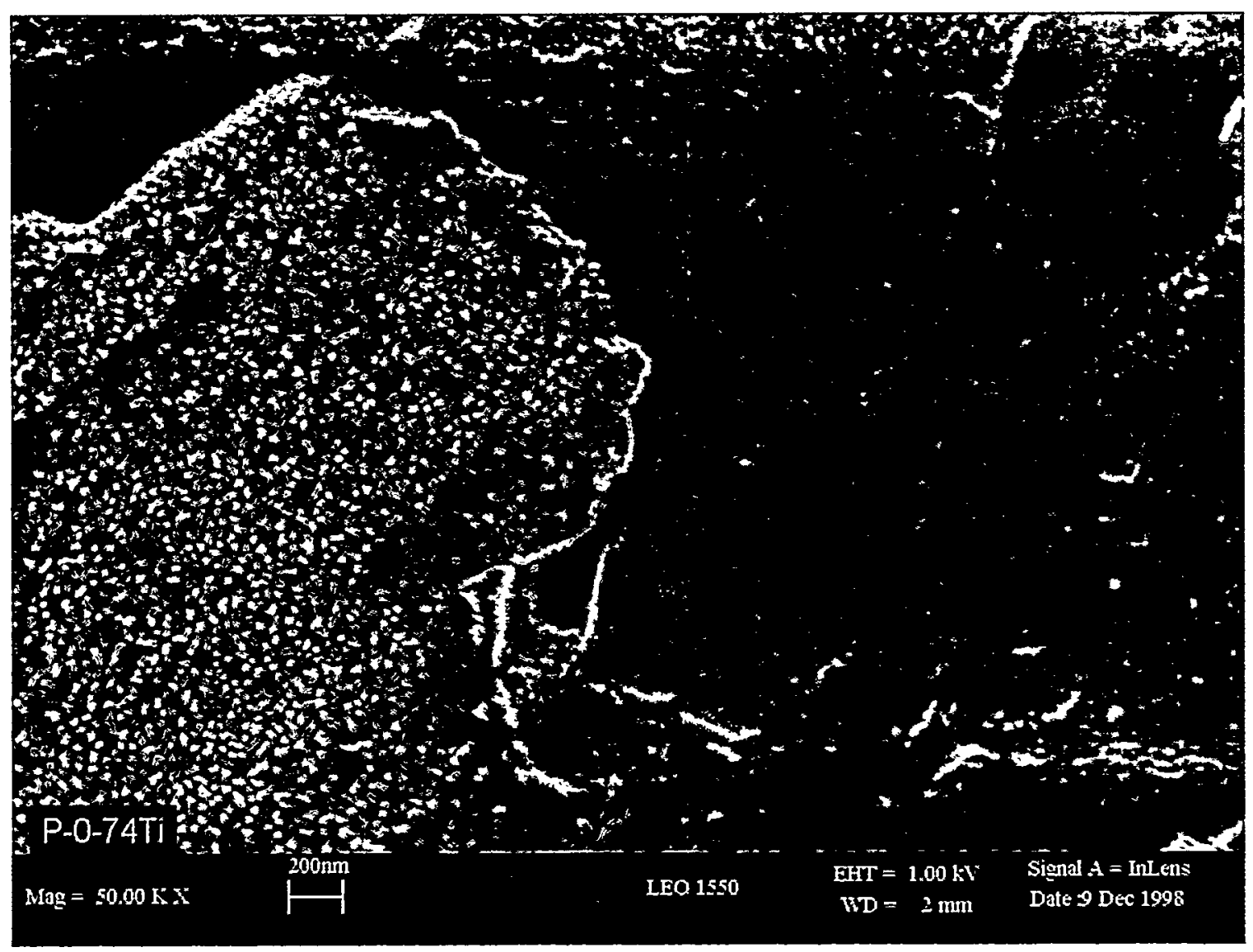

Figure 8: Field emission SEM of the metal failure surface of a PETI-5 NCA specimen. 


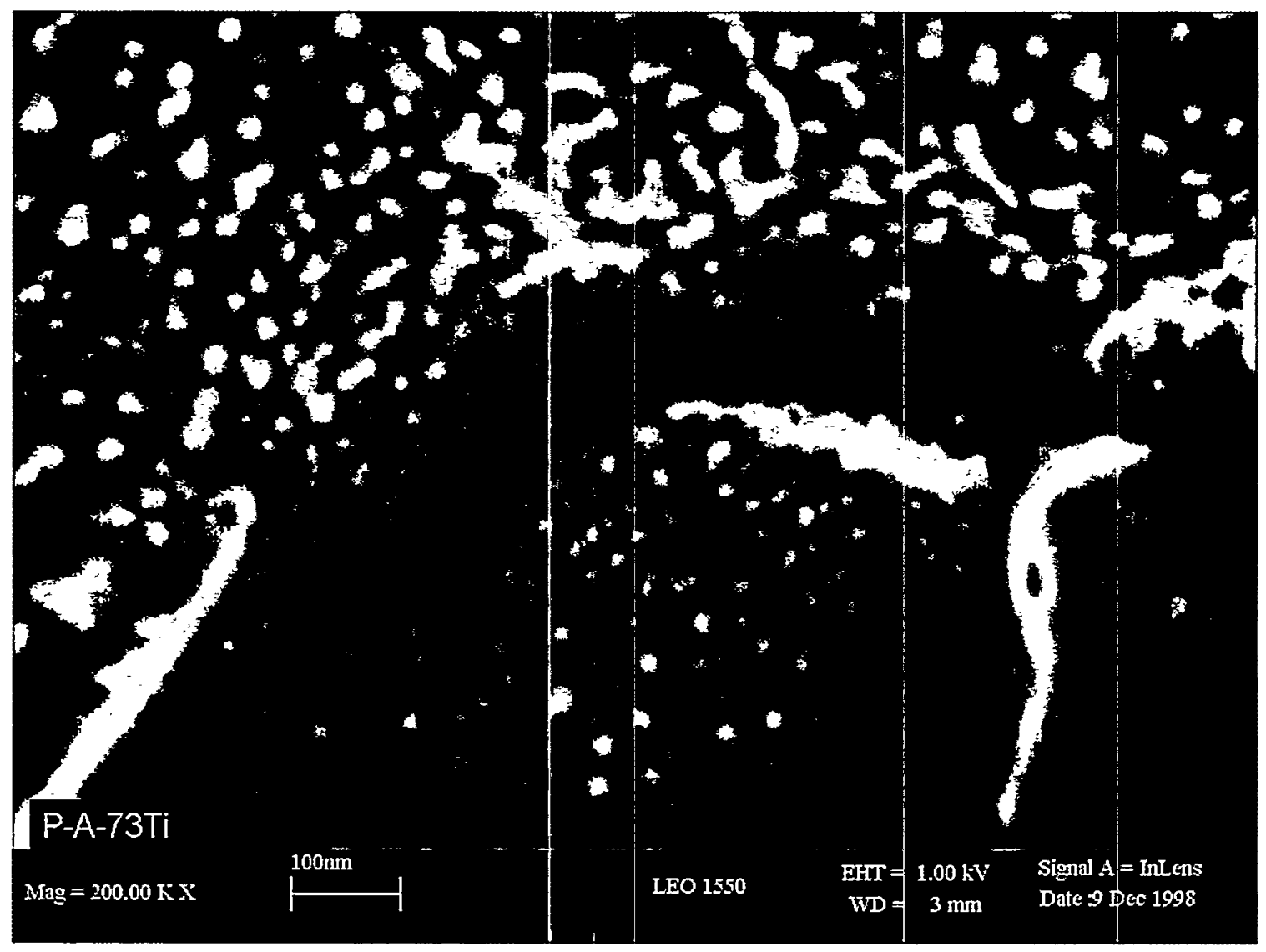

Figure 9: Field emission SEM of the metal failure surface of a PETI-5 NCA specimen. 


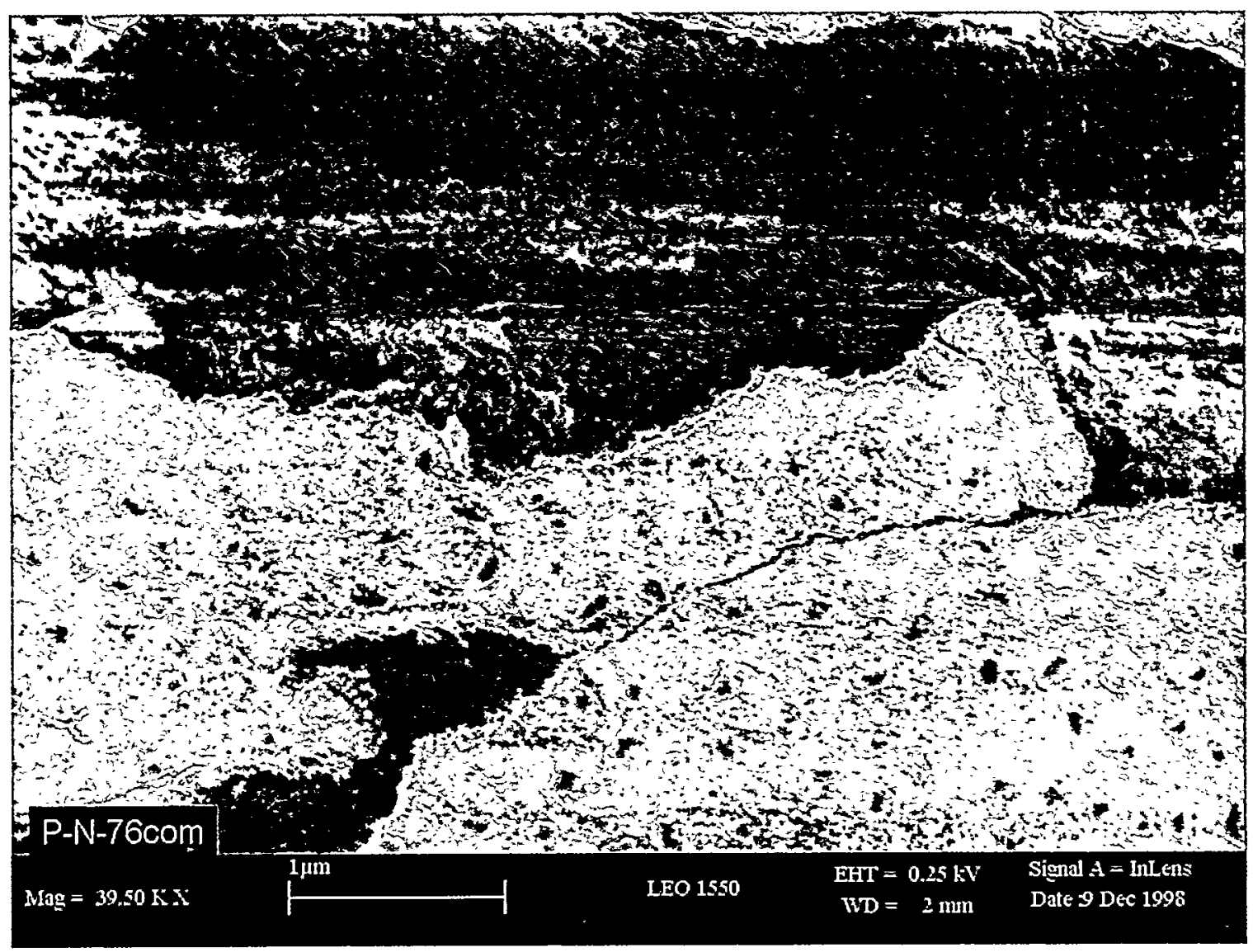

Failure direction

Figure 10: Field emission SEM of the adhesive failure surface of a PETI-5 NCA specimen. 


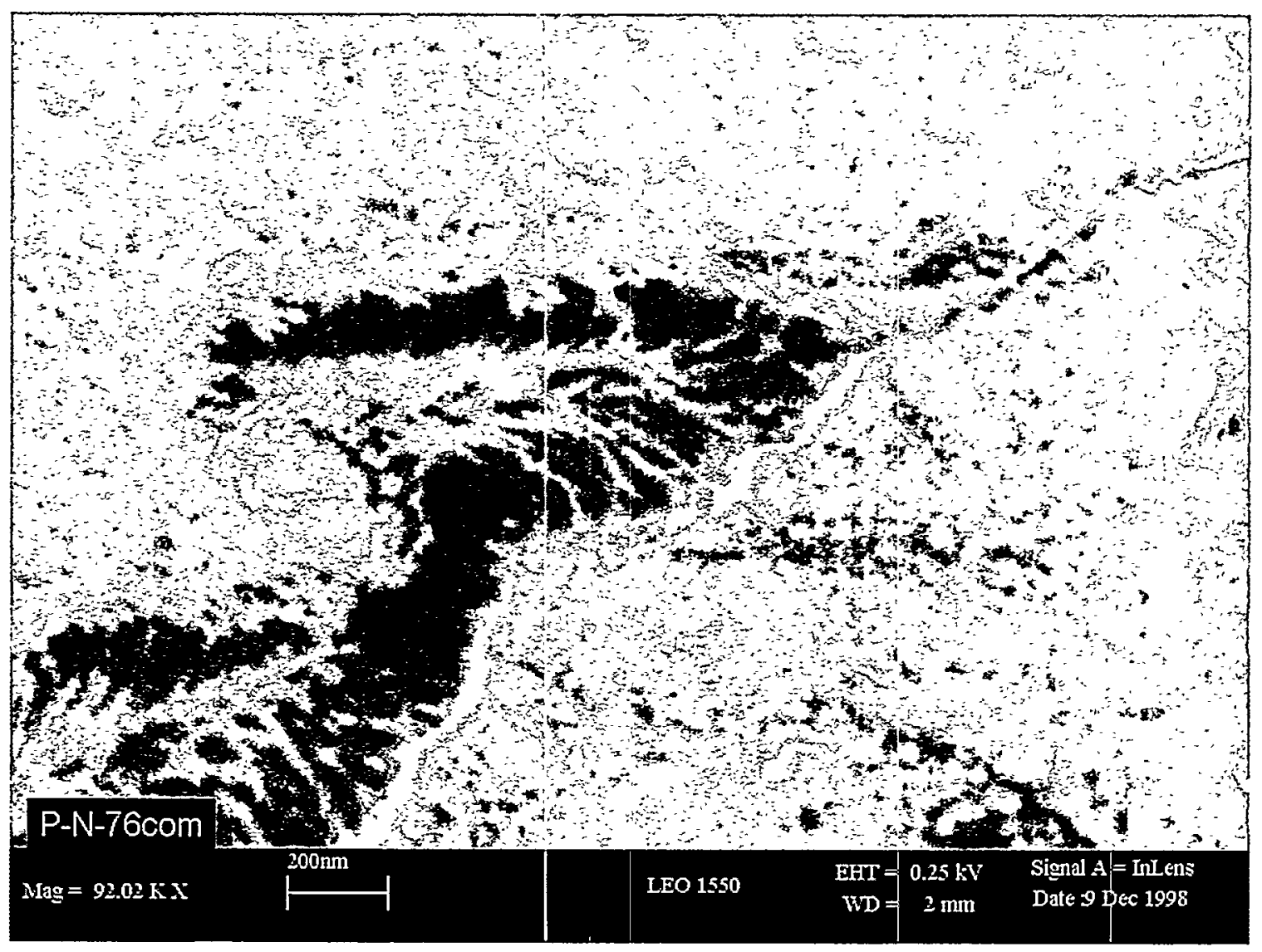

Figure 11: Field emission SEM of the adhesive failure surface of a PETI-5 NCA specimen. 


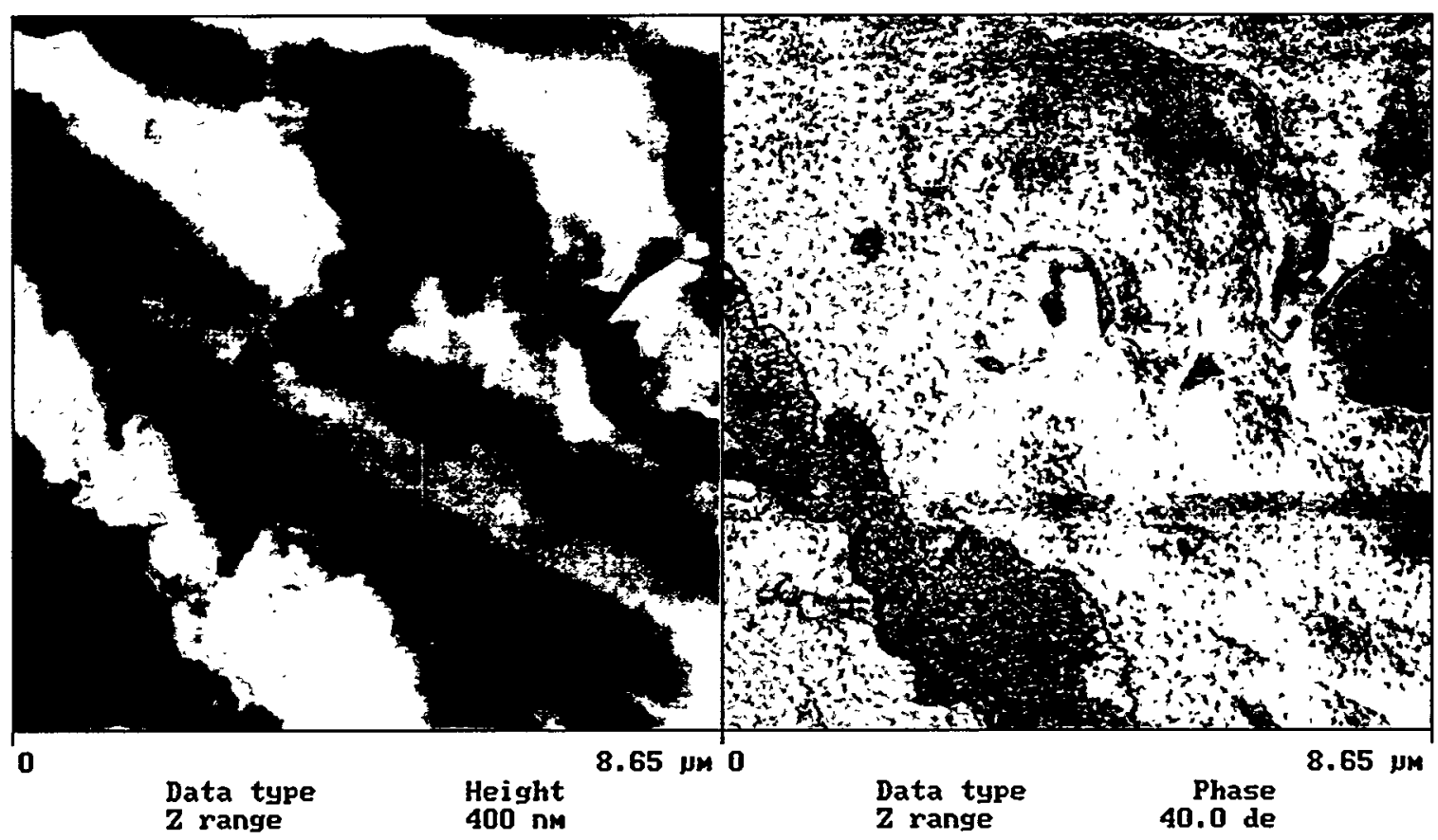

Figure 12: Height (left) and phase (right) atomic force microscopy images of the metal failure surface of a PETI-5 NCA specimen 


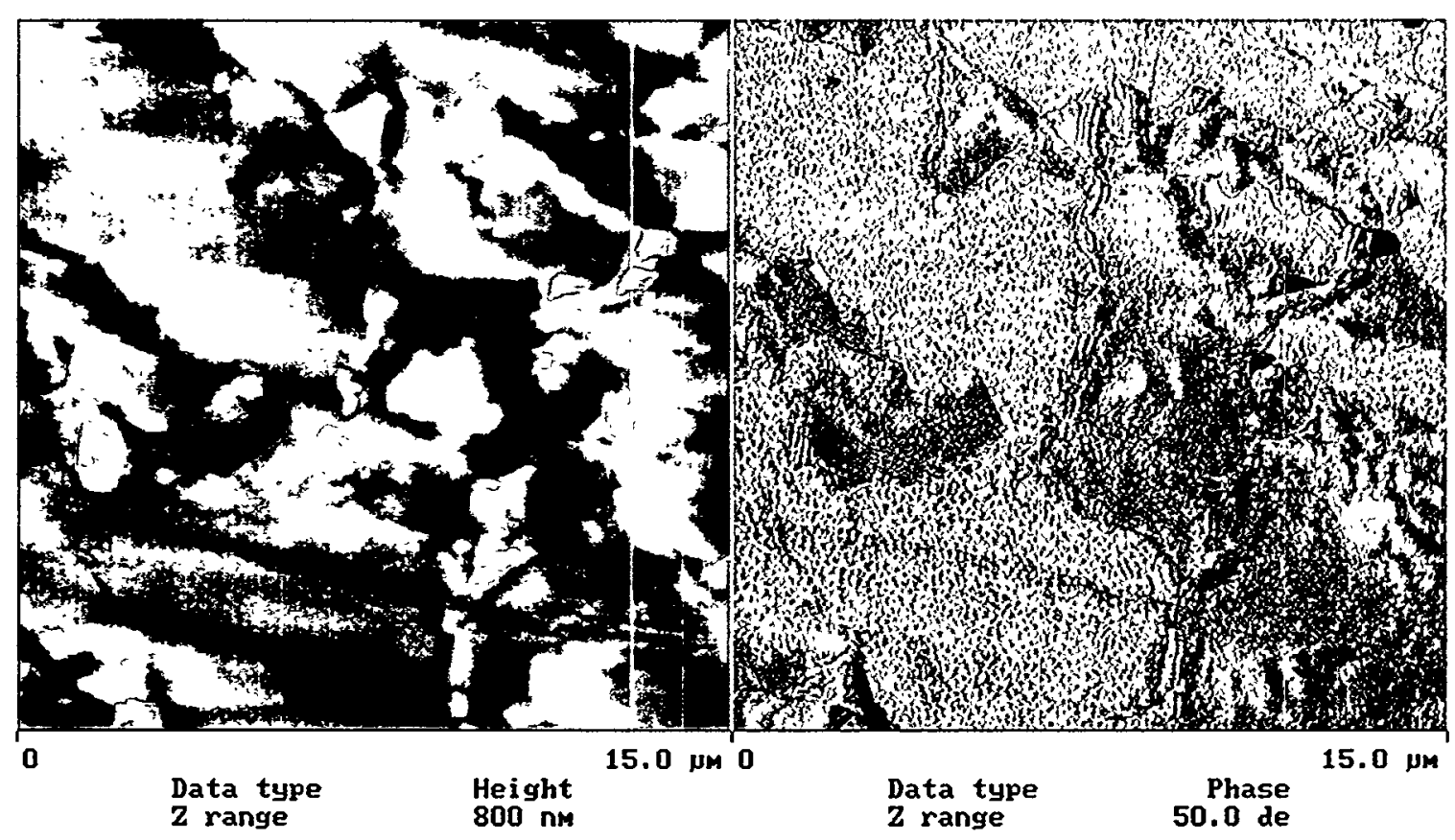

Figure 13: Height (left) and phase (right) atomic force microscopy images of the adhesive failure surface of a PETI-5 NCA specimen. 
(a)

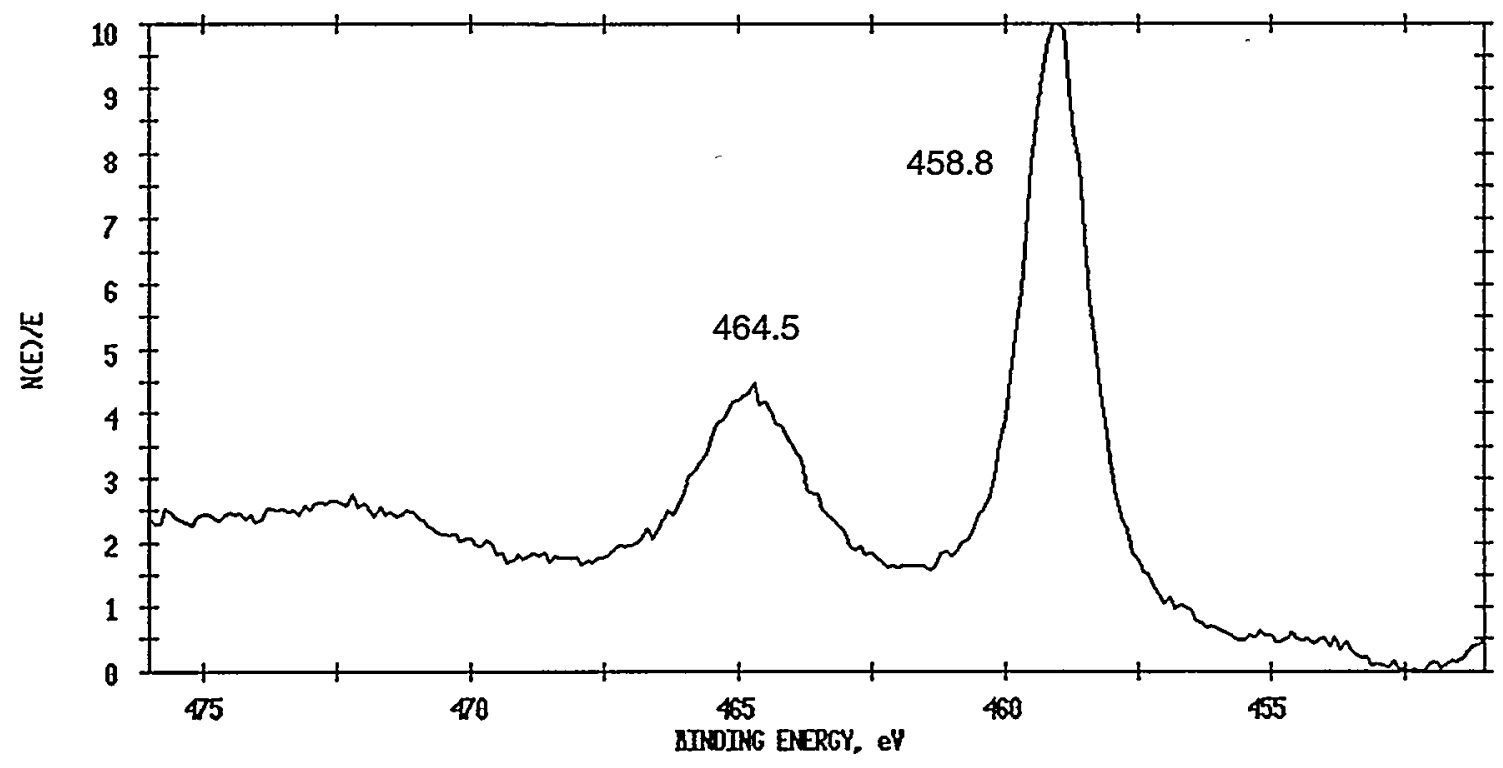

(b)

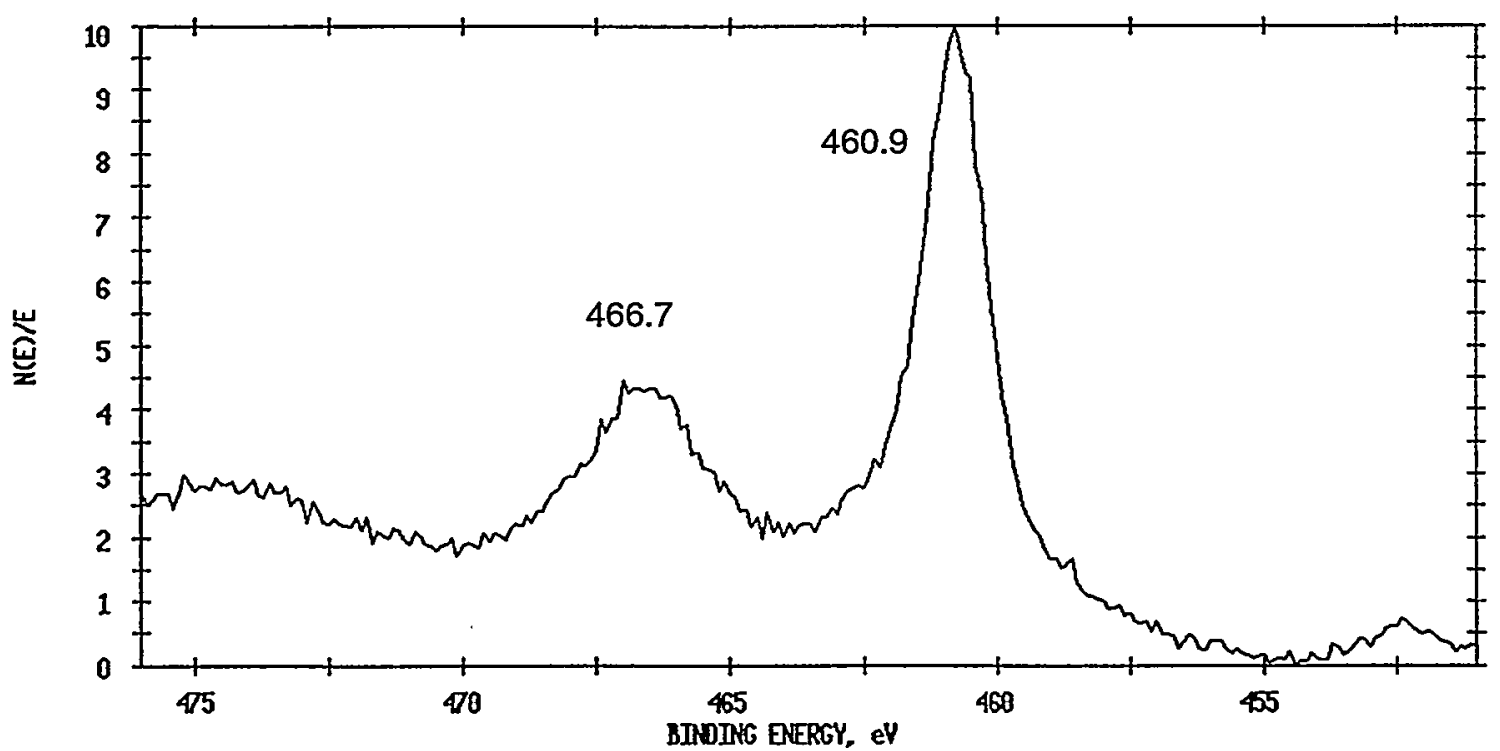

Figure 14: Ti 2p $3 / 2$ XPS spectra from (a) PETI-5 metal failure surface and (b) PETI-5 adhesive failure surface. Note: Each spectrum is on a normalized $x$-axis scale; as shown, peak heights and areas cannot be compared between the two spectra. 
(a)

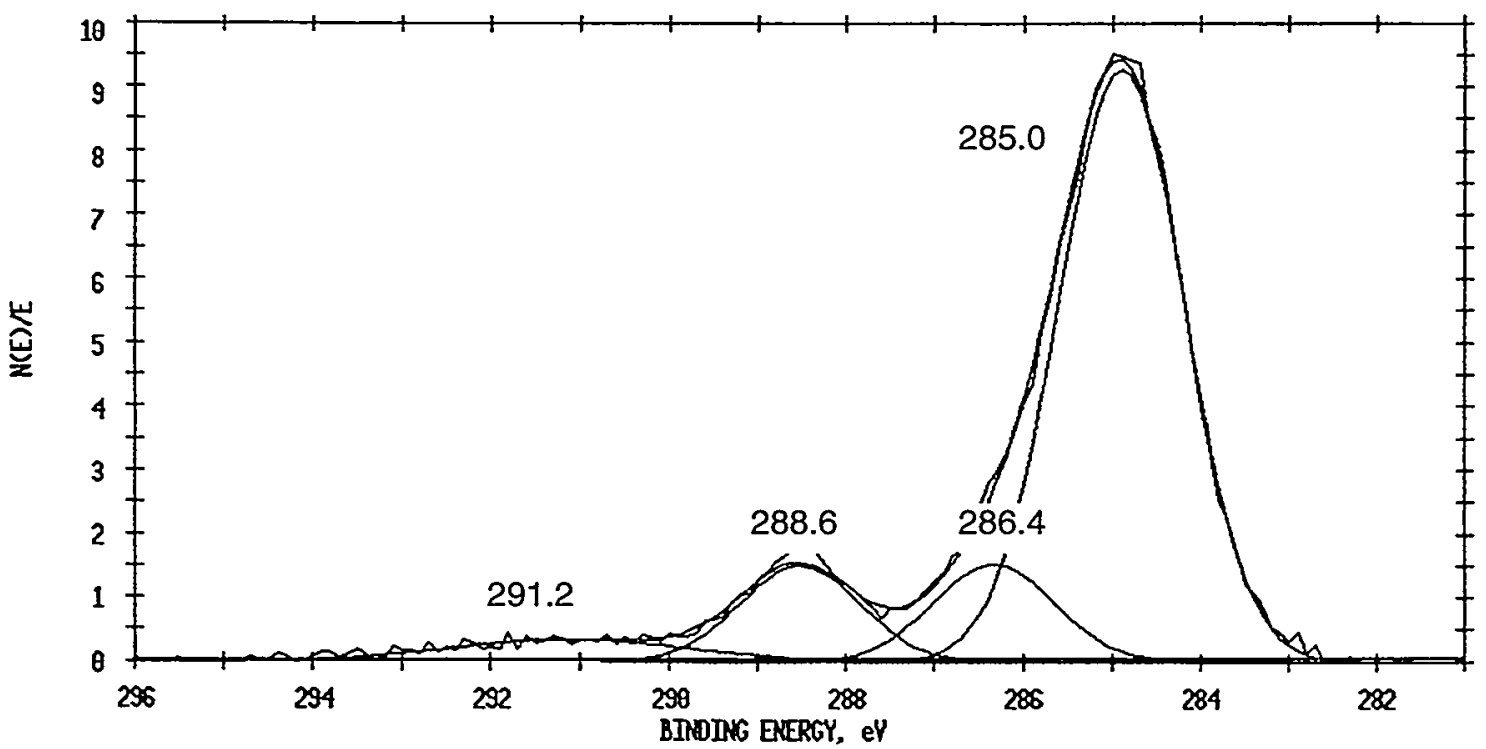

(b)

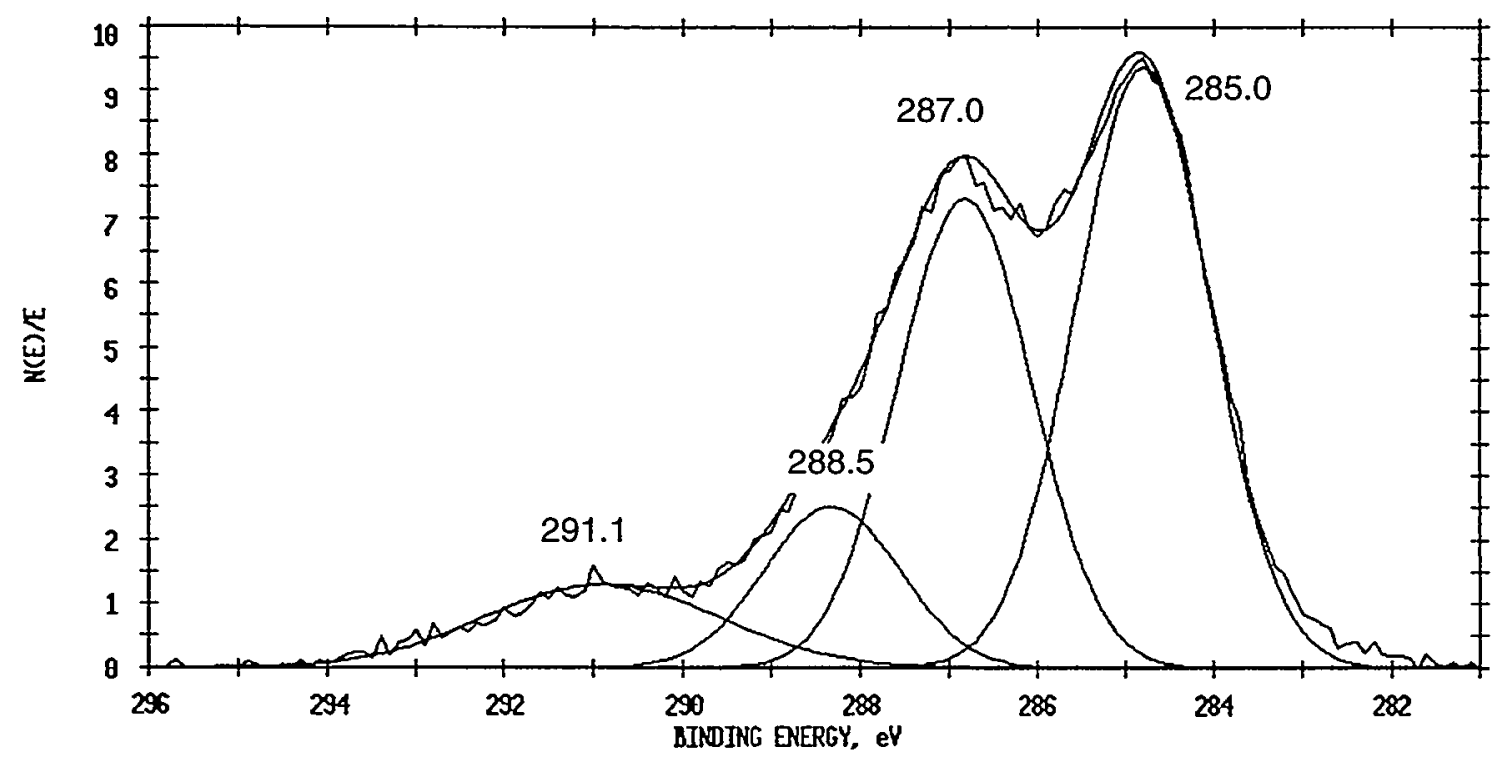

Figure 15: C 1s XPS spectra from (a) PETI-5 metal failure surface and (b) PETI-5 adhesive failure surface. Note: Each spectrum is on a normalized $x$-axis scale; as shown, peak heights and areas cannot be compared between the two spectra. 


\section{Shifted Carbon as a Function of Titanium \\ Concentration}

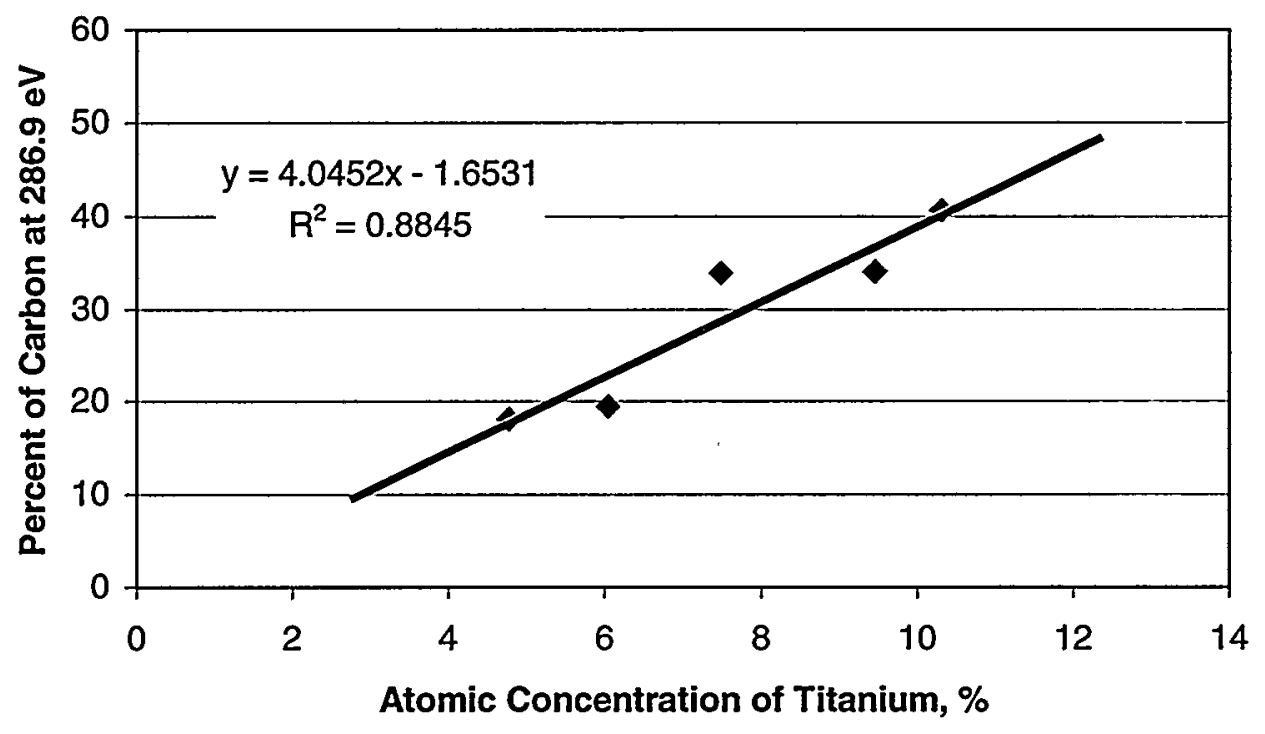

Figure 16: From XPS analysis of the PETI-5 adhesive failure surface, percent of the $C 1 \mathrm{~s}$ photopeak that is shifted to $286.9 \mathrm{eV}$ as a function of titanium coverage. 
(a)

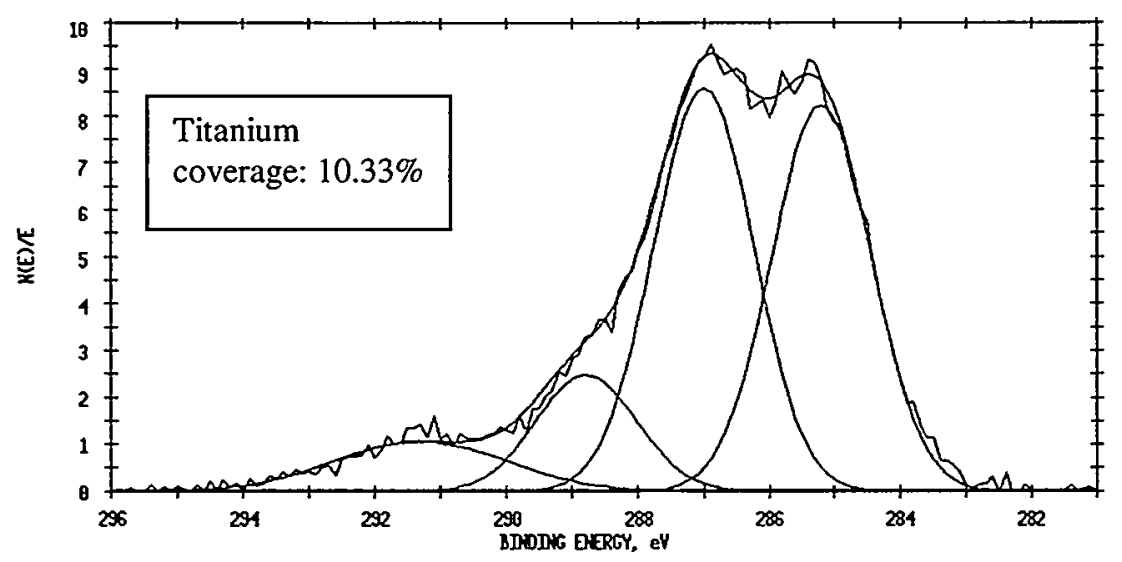

(b)

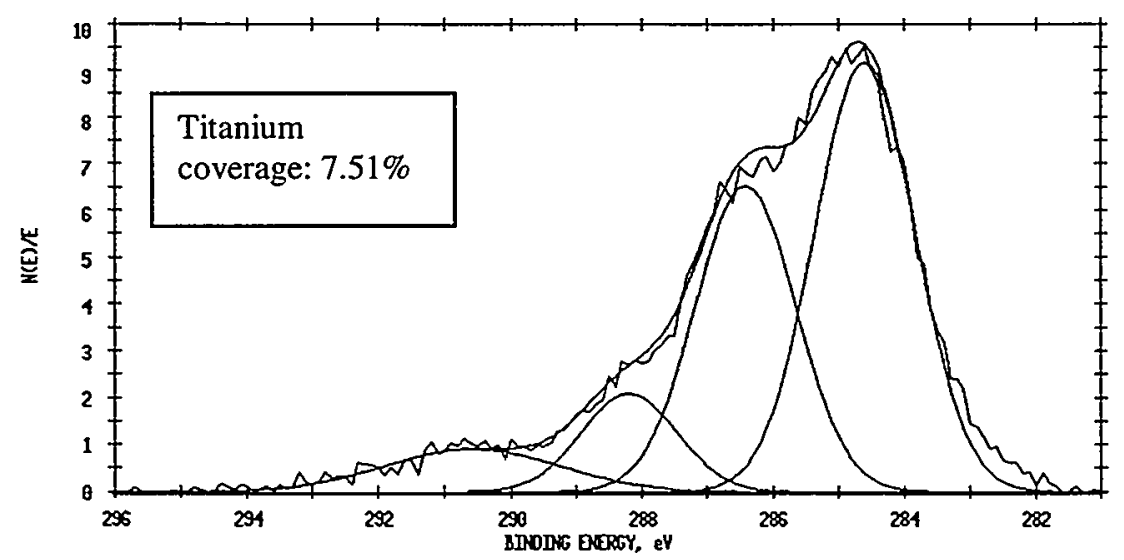

(c)

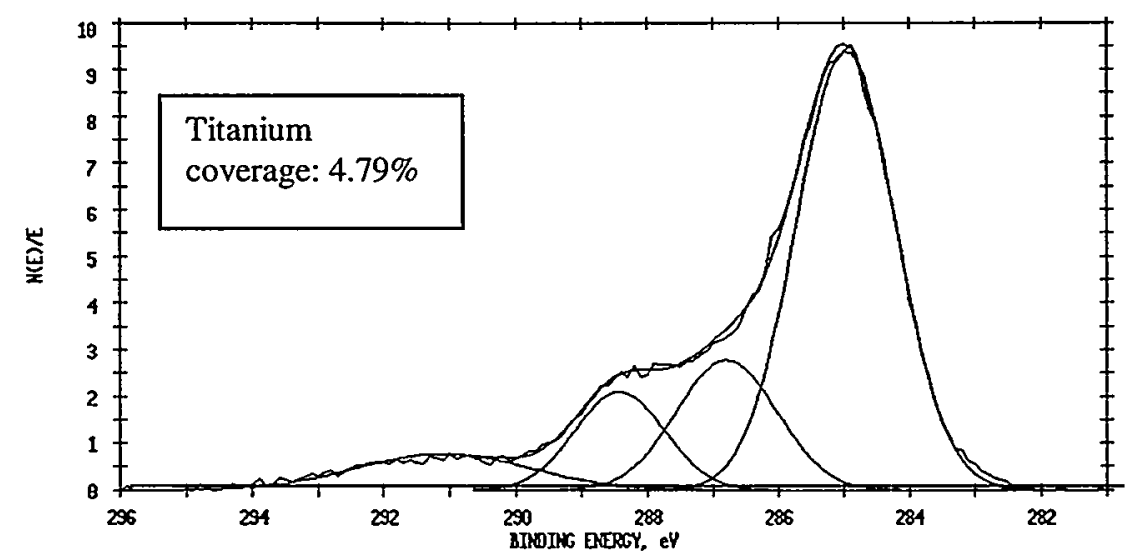

Figure 17: C 1s XPS spectra from PETI-5 adhesive failure surfaces with varying titanium coverage. Note: Each spectrum is on a normalized $x$-axis scale; as shown, peak heights and areas cannot be compared among the three spectra. 